\title{
Separation of diethyl phthalate from water by pervaporation
}

\author{
MAHDI BOURASSI ${ }^{1,2}$, EMMA HUMBERT MARTIN $^{3}$, MELANIE BOURRE $^{4}$, VLASTIMIL FILA $^{5}$ \\ AND JANA GAALOVA ${ }^{1, *}$
}

\author{
${ }^{1}$ Institute of Chemical Process Fundamentals of the ASCR, v.v.i \\ Rozvojova 135, 16500 Prague 6 \\ CZECH REPUBLIC \\ ${ }^{2}$ Faculty of Science Institute for Environmental Studies, Charles University \\ Benátská 2, 12801 Prague 2 \\ CZECH REPUBLIC \\ ${ }^{3}$ Department of chemistry, IUT of Poitiers \\ 14 allée jean monnet - bat c.12, tsa 41114, 86073 Poitiers cedex \\ FRANCE \\ ${ }^{4}$ Université de Limoges \\ 33 rue François Mitterrand, BP 23204, 87032 Limoges \\ FRANCE \\ ${ }^{5}$ University of Chemistry and Technology \\ Technická 5, 16628 Prague 6 \\ CZECH REPUBLIC \\ *corresponding author: Jana Gaálová, e-mail: gaalova@icpf.cas.cz
}

\begin{abstract}
Seventeen different kind of membranes - based on Matrimid, Ultem polymers and DAM/DABA - were prepared and applied for pervaporation of diethyl phthalate from water. They were compared to the commercial materials like PDMS, PP and PS. The components of active layer played a crucial role on membrane process. Newly prepared membranes showed an exceptional sorption capacity (up to $100 \%$ ) comparing to the commercial membranes (around $20 \%$ ), all by reaching equivalent pervaporation results of all tested membranes

(close to $40 \%$ ). The fastest permeation was achieved by raising the temperature to $50{ }^{\circ} \mathrm{C}$ with PDMS membrane, reaching total elimination of DEP. Diethyl phthalate was preferentially passing through the membranes due to dissimilar affinity of the separation materials.
\end{abstract}

Key-Words: - pervaporation, diethyl phthalate, water.

Received: September 11, 2020. Revised: January 10, 2021. Accepted: January 18, 2021. Published: February 2, 2021.

\section{Introduction}

Emerging Contaminants (ECs) present one of the most challenging environmental problem. The problem is emphasized by a large structural variety of the compounds, affecting even at trace concentration, bioaccumulation for of low biodegradability, and persistent in Wastewater Treatment (WWT) effluents [1, 2]. Categorizing these ECs can be complex due to diverse sources, uses and effects; e.g. Pharmaceuticals (PhACs), Personal Care Products (PCPs), Endocrine Disrupting Compounds (EDs), Antibiotics (ATBs) etc. The main sources of ECs are industrial manufactories, agricultural chemicals, hospitals, and domestic. The compounds are released by different ways to the environment - water (wastewater), air (airborne deposition for volatile compounds) or soil (adsorption). EDs can affect different environments biota, also humans via different type of expositions. Many researchers reported the presence of these compounds (e.g. Phthalates) in food packing materials, outdoor and indoor air, ground and surface water, and in some fruits and vegetables around the globe [3-6].

Plastics invaded our daily life used materials. Phthalates Esters (PAEs) are widely applied as plasticizer for different plastic and other products like resin, constructive materials, food and drinks packing, PCP, polycarbonates, Flame retardant in furniture and households etc. [7, 8]. PAEs, only physically bounded to the materials $[9,10]$, may be easily leached by solvents and evaporate in the air [6]. Therefore, PAEs can be found almost 
everywhere: packed food, drinks, soil, water biota, tissues and so on. Leached or evaporated from daily used materials. The most direct source to human body of this contamination coming from bottled water and packed food [11]. Globally bottled water industry production is exceeding milliard litters per year, and it is continually rising each year. Even though different studies reported the contamination of mineral water from the source, due to groundwater contamination [12-14]. And the presence of PAEs the environment present many risks for human health and biota [15]. The exposition of Zebra fishes to PAEs presented estrogenic and endocrine distrusting effects [16]. Moreover other studies reported that these PAEs including DEP are identified as endocrine distributor affecting various vital organism like thyroid receptors, male fertilities by decreasing sperms concentration, carcinogenic effects, hepatic and renal dieses, asthma and allergy, cardiovascular system, or hemostasis [17-19].

World Health Organization (WHO) and European union Environmental with Planning Law Department had published the tolerated daily intake of phthalate $[20,21]$. To respect those regulations and environment sustainable protection, advanced wastewater treatments are necessary. Some researcher focus on Advanced Oxidation Processes (AOPs) performed mainly in pilot scale. The technology allows to mineralize directly ECs [2224]; still, environmental impact assessment and experience are required for full scale applications $[25,26]$. Ozonation, Activated Carbon or Membrane filtrations are already used in full-scale mainly in Europe, Australia and America [26-28]. Nevertheless, Ozonation struggle with by-products which can be harmful for the environment. Activated Carbone require high energy for preparation, and concentrated waste management is challenging after adsorption process. And membrane filtrations suffer from fulling. Furthermore, by-products and concentrated solution can be far more challenging to handle and manage [25, 29]. Advanced treatments must be further studied.

Pervaporation is a membrane separation method frequently used to dehydrate organic substances forming azeotropic mixtures with water; e.g. methanol [30], ethanol [31, 32], or isopropyl alcohol [33]. It is also used for desalination of sea water [34] and waste water treatment [35]. The mixture is divided by partial evaporation through a non-porous membrane, made of ceramic or polymeric (homogeneous and composite) materials. Polydimethylsiloxane membranes are typical example of homogenous materials, based on one polymer [36]. Composite ones contains two or more polymers, e.g. a polyvinyl alcohol layer deposited on a polysulfone and a polyester [33]. The polymers may have an internal microporousity (PIM), too [37]. Among various membranes suitable for pervaporation [38-40], Metal Organic Framework (MOF) [41], zeolites [42] or silica based materials [43] are well known candidates.

During pervaporation, one side of tested membrane is in direct contact with the separating liquid mixture, the other side always with the separated component (pervaporate) desorbed into low pressure medium - vacuum. It offers a low energy consumption due to mild conditions and separation of mixtures that cannot be exposed to higher temperatures without the need to mix other substances. The separation of the mixture itself takes place on the basis of the different affinities of the each component for the membrane and their different transport rates within the membrane. Therefore, the final composition of the pervaporate may not correspond to liquid-vapor equilibrium. It depends on solubility and diffusion coefficient of the components, which is also the control process of the separation, and its driving force is the pressure gradient [38, 44].

The present paper focuses on water purification from DEP, applying different flat organophilic membranes in sorption and pervaporation processes. The membrane with incorporated different amount of fillers such as graphene oxide and TS-1 zeolite were compared to several commercial hydrophobic membrane, suitable for pervaporation process. During pervaporation, the influence of a temperature was also investigated.

\section{Experimental part}

\subsection{Materials}

The flat-sheet, composite membranes with organophilic surface properties were chosen for sorption and pervaporation tests. Their characteristics are given in Error! Reference source not found.. The materials were based on Ultem, Matrimid and 6FDA-DAM:DABA 3:1 and different types of filling materials was added into the matrix. In case of Matrimid and 6FDA-DAM:DABA 3:1 the different fraction of graphene oxide was added, TS-1 zeolite $(\mathrm{Si} / \mathrm{Ti}=100)$ was added into the Matrimid.

Graphene oxide membrane was prepared by graphite oxidation via the improved Hummers method, also called the Tour method, according to the procedure described by Jankovsky et al [45].

TS-1 zeolite particles were prepared by hydrothermal synthesis from mother solution obtained by rapid mixing of two individually 
Table 1. Characteristics of tested membranes.

\begin{tabular}{|c|c|c|c|c|c|}
\hline Membrane & Type/Filler & Material & $\begin{array}{l}\text { Thickness } \\
\text { (mm) }\end{array}$ & $\begin{array}{l}\text { Diameter } \\
(\mathrm{mm})\end{array}$ & $\begin{array}{l}\text { Weight } \\
\text { (mg) }\end{array}$ \\
\hline \multirow{4}{*}{ Ultem } & No filler & \multirow{4}{*}{ Ultem } & \multirow{4}{*}{0.05} & \multirow{4}{*}{4} & \multirow{4}{*}{0.04} \\
\hline & GO* $0.5 \%$ & & & & \\
\hline & GO* $2.5 \%$ & & & & \\
\hline & GO* 5\% & & & & \\
\hline \multirow{5}{*}{ Matrimid } & No filler & \multirow{5}{*}{ Matrimid } & \multirow{2}{*}{0.04} & \multirow{2}{*}{4} & \multirow{2}{*}{0.04} \\
\hline & TS-1 Z* $10 \%$ & & & & \\
\hline & TS-1 Z* 20\% & & \multirow{3}{*}{0.05} & \multirow{3}{*}{4} & \multirow{3}{*}{0.04} \\
\hline & TS-1 Z* 30\% & & & & \\
\hline & ETS - $10 \quad Z^{*} 30 \%$ & & & & \\
\hline \multirow{4}{*}{$\begin{array}{c}\text { 6FDA- } \\
\text { DAM:DABA 3:1 }\end{array}$} & No filler & \multirow{4}{*}{$\begin{array}{c}\text { 6FDA- } \\
\text { DAM:DABA } \\
3: 1\end{array}$} & \multirow{4}{*}{0.04} & \multirow{4}{*}{4} & \multirow{4}{*}{0.03} \\
\hline & GO* $0.5 \%$ & & & & \\
\hline & GO* $2.5 \%$ & & & & \\
\hline & GO* 5\% & & & & \\
\hline PERVAP $^{\mathrm{TM}}$ & 4060 & PDMS & 0.200 & 30 & 95.9 \\
\hline PP & - & $\mathrm{PP}$ & 0.004 & 38 & 4.2 \\
\hline PS & - & PS & 0.029 & 38 & 34.7 \\
\hline
\end{tabular}

prepared solutions A and B. Solution A (the silica source) was prepared by mixing the desired amount of TEOS (tetraethoxysilane) and TPAOH (tetrapropylammonium hydroxide), while solution B (titanium source) was prepared by mixing TBOT (titanium (IV) n-butoxide) and 2-propanol. After the addition of water to reach the final molar ratio of the solution $0.01 \quad \mathrm{TiO}_{2}: 1 \quad \mathrm{SiO}_{2}: 0.18$ TPAOH:75 $\mathrm{H}_{2} \mathrm{O}$ followed the hydrolysis and hydrothermal step. The detailed procedure description can be found in the work [46].

Polymers used as continuous phases were commercial polyimide Matrimid ${ }^{\circledR} 5218$ kindly supplied by Huntsman, commercial polyetherimide Ultem ${ }^{\circledR} 1000$ supplied by SABIC, and 6FDADAM:DABA 3:1 synthesized in our laboratory. The polyimide 6FDA-DAM:DABA 3:1 was synthesized using a two-step polycondensation reaction (synthesis of polyamic acid and thermal imidization in solution) as described in work [47].

Commercial PDMS membrane PERVAP 4060 was purchased from DeltaMem AG. PERVAP 4060 is a thin film composite membrane consisting of PDMS thin layer and PET (polyethylene terephthalate) porous support. The membrane is commonly used for organophilic pervaporation. PS and PP are clear dense polymeric films purchased from GoodFellow Cambridge Ltd.

Diethyl Phthalate (DEP) purity $99.5 \%$ purchased from Sigma-Aldrich was used as model pollutant. Ultrapure water given from purification system
(Simpli Lab, Millipore S. A., Molsheim, France) set up at institute laboratory.

\subsection{Methods}

Membrane testes were carried out using pervaporation set-up at laboratory equipment of the Institute of Chemical Processes of the Academy of Sciences of the Czech Republic, schematized in Fig. 1 . The set-up is composed of three glass reactor cells. Cells temperature is controlled using thermostat Julabo F25 $\left(25-50^{\circ} \mathrm{C}\right)$. The volume of $150 \mathrm{~mL}$ of DEP solution $(300 \mathrm{mg} / \mathrm{L})$ has been in contact with membrane, placed at position 1 of the schema inside glass reactor, during whole experiment. The model wastewater solution has been stirred by magnetic stirrers. The circular surface of each tested membrane was equal $2.05 \mathrm{~cm}^{2}$. DEP that permeated through tested membrane has been collected in cooling trap. This was maintained at $-25^{\circ} \mathrm{C}$ with vacuum applied at the permeate site as a driving force enhancer (80 $\mathrm{KPa}$ ).

Each membrane has been applied in the sorption experiment in order to inspect the affinity of DEP towards the membrane as well as a membrane capacity. DEP solution of concentration $70 \mathrm{mg} / \mathrm{L}$ was introduced in clean dark glass bottle. A round shape piece of the tested membrane $(2.2 \mathrm{~cm}$ diameter) was inserted into $50 \mathrm{ml}$ of DEP solution. The membranes kept swaying in the solution by mechanical agitator Witeg Lbortechnik GmbH, SHO Orbital Shaker set on 115 RPM AT $25^{\circ} \mathrm{C}$. 


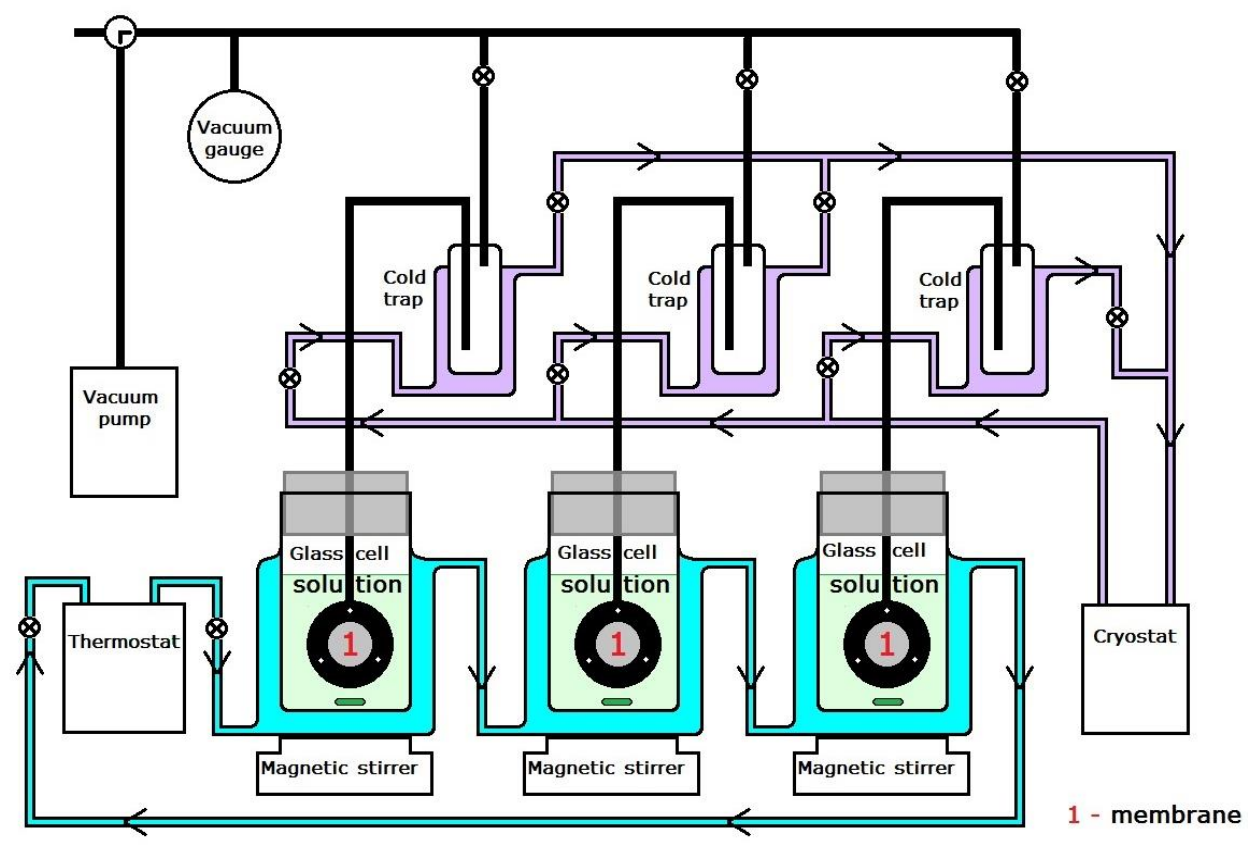

Fig 1. Pervaporation set-up

\subsection{Sample analysis}

HPLC measurements were carried out on a Dionex 3000 Ulti Mate HPLC from Thermo Scientifics equipped with a binary pump, degasser, diode array detector (DAD), solvent tray and an auto sampler. The used chromatographic column was Luna C18 (5 $\mu \mathrm{m}, 4.6 \times 150 \mathrm{~mm}$, Phenomenex). The detection wavelength was $254 \mathrm{~nm}$. The method for HPLC used isocratic flow of mobile phase composed of $90 \%$ acetonitrile and $10 \%$ ultra-pure water with $0.1 \%$ formic acid as buffer. Temperature was $20-22{ }^{\circ} \mathrm{C}$ and flow rate was $0.5 \mathrm{~mL} / \mathrm{min}$ for total time of $10 \mathrm{~min}$.

\subsection{Flux}

Flux is a key parameter of membrane processes. The eq. (1) was used to calculate the flux of pervaporation experiment. $J$ parameter depends on permeate mass mPermeate diffused through specific surface area $A$ of tested membrane, during a time interval $\Delta t$. The flux is expressed on $\mathrm{mg} / \mathrm{h} \cdot \mathrm{m}^{2}$.

$$
\boldsymbol{J}=\frac{\boldsymbol{m}_{\text {Permeate }}}{\Delta \boldsymbol{t} \boldsymbol{A}}
$$

\section{Results and discussion}

In frame of screening various membranes, the separation materials have been tested in sorption tests of DEP. Starting concentration of DEP in water was $70 \mathrm{mg} / \mathrm{L}$. All laboratory made membranes were capable to adsorb total amount of DEP during the time of experiments; except membranes based on Matrimid, which were saturated before the end of experiment. A small peak of DEP was visible by
HPLC for this material even at $45^{\text {th }}$ day of sorption. On the contrary, the membranes DAM:DABA have proven to be the fastest sorbents: $50 \%$ of DEP in 6 days. The rest of tested membranes, based on Ultem, have showed a medium sorption capacity. An explication of influence of different fillers is being proceeded.

Newly prepared membranes showed an exceptional sorption capacity (up to $100 \%$ of sorbed DEP) comparing to the commercial membranes (up to $20 \%$ for PDMS, PP and PS).

Pervaporation tests were proceeded with laboratory made membranes. Four of them are presented as an example in Table 2.

Fig. 2. shows DEP elimination from water using different membranes described in Table 2.
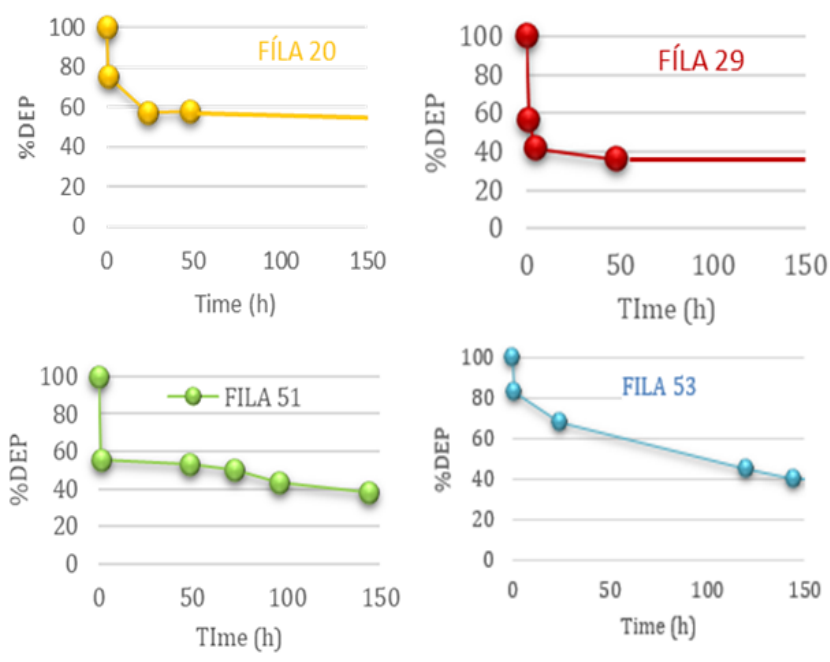

Fig 2. DEP elimination using different membranes. 
Table 2 . The pervaporation tests applying the membranes made in laboratory.

\begin{tabular}{|c|c|c|c|c|c|c|}
\hline Membrane & Abbreviation & $\begin{array}{c}\text { Temperature } \\
\left({ }^{\circ} \mathrm{C}\right)\end{array}$ & $\begin{array}{l}\text { c DEP } \\
(\mathrm{mg} / \mathrm{L})\end{array}$ & $\begin{array}{c}\text { Thickness } \\
(\mathrm{mm})\end{array}$ & $\begin{array}{c}\text { Active surface } \\
\left(\mathrm{cm}^{2}\right)\end{array}$ & $\begin{array}{l}\text { Weight } \\
(\mathrm{g})\end{array}$ \\
\hline Ultem GO* $2.5 \%$ & FILA 20 & \multirow{4}{*}{25} & \multirow{4}{*}{70} & 0.04 & \multirow{4}{*}{3.6} & 0.03 \\
\hline Ultem GO* $0.5 \%$ & FILA 29 & & & 0.05 & & 0.04 \\
\hline Matrimid TS-1 Z* $10 \%$ & FILA 51 & & & 0.05 & & 0.04 \\
\hline Matrimid TS-1 Z* 20\% & FILA 53 & & & 0.05 & & 0.04 \\
\hline
\end{tabular}

FILA 51 and 53 (in green and blue below) are both based on Matrimid, however, a difference between their pervaporation activities is visible, depending on $\%$ of zeolite. Membrane 51 allows pervaporation of almost $50 \%$ of DEP within the $1^{\text {st }}$ hour, while the membrane 53 is slower. Still, both reach $40 \%$ of DEP in the feed in $150 \mathrm{~h}$.

FILA 29 and 20 (in red and yellow below) are again - made of similar material, Ultem, with noticeable differences in pervaporation process, in favor to the membrane 29 with higher amount of graphene oxide.
Commercial membranes reached similar pervaporation results than laboratory made separation materials, up to $40 \%$ of eliminated DEP. The results have also confirmed expected: the free volume of polymer at higher temperature $\left(50{ }^{\circ} \mathrm{C}\right)$ expands and eases the transfer of DEP through the PDMS membrane, avoiding a saturation (in red and blue for the experimental temperature 25 and $30{ }^{\circ} \mathrm{C}$ respectively).

The flow of all tested membranes was between $250-50 \mathrm{mg} / \mathrm{L} \cdot \mathrm{m}^{2} . h$. These dissimilarities are linked to a nature of separation material.

Table 3. The pervaporation tests applying the commercial membranes.

\begin{tabular}{|c|c|c|c|c|c|c|}
\hline Test & Membrane & $\begin{array}{c}\text { Temperature } \\
\left({ }^{\circ} \mathrm{C}\right)\end{array}$ & $\begin{array}{l}\text { c DEP } \\
(\mathrm{mg} / \mathrm{L})\end{array}$ & $\begin{array}{c}\text { Thickness } \\
\text { (mm) }\end{array}$ & $\begin{array}{l}\text { Active surface } \\
\left(\mathrm{cm}^{2}\right)\end{array}$ & $\begin{array}{l}\text { Weight } \\
\text { (g) }\end{array}$ \\
\hline 1 & \multirow{3}{*}{$\begin{array}{l}\text { PERVAPTM } \\
4060\end{array}$} & 25 & \multirow{3}{*}{70} & \multirow{3}{*}{0.18} & \multirow{3}{*}{3.6} & \multirow{3}{*}{0.05} \\
\hline 2 & & 30 & & & & \\
\hline 3 & & 50 & & & & \\
\hline
\end{tabular}

Pervaporation tests detailed in Table 3 were progressed with commercial membrane. The tests should serve as references to the laboratory made separation materials. The tests were carry on at the different temperatures as well (an example of PDMS in Fig. 3.).

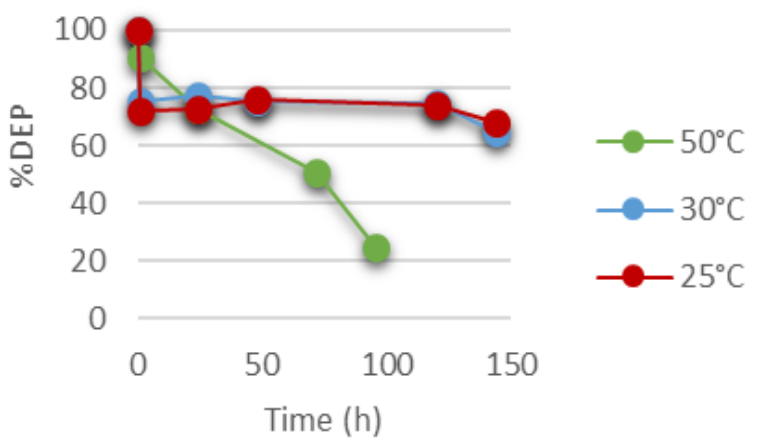

Fig. 3. Elimination of DEP from water in time by commercial membranes.

\section{Conclusion}

Different kind of membranes, based on Matrimid, Ultem polymers and DAM/DABA, were prepared and applied for pervaporation of diethyl phthalate from water, systematically compared to the commercial materials such as PDMS, PP and PS. Newly prepared membranes showed an exceptional sorption capacity (up to $100 \%$ ) comparing to the commercial membranes (around $20 \%$ ). The components of active layer played a main role on membrane process. The materials based on Ultem, Matrimid and 6FDA-DAM:DABA 3:1 showed that different types of filling materials added into the matrix have their optimum with respect to the final efficiency of the membrane process. In case of Matrimid and 6FDA-DAM:DABA 3:1 $0.5 \%$ of graphene oxide was the most optimal, while $10 \%$ of TS-1 zeolite ( $\mathrm{Si} / \mathrm{Ti}=100)$ added into the Matrimid is slightly more advantageous than $20 \%$. Nevertheless, all tested membranes - laboratory and commercial reached similar final pervaporation results, up to 
$40 \%$ of eliminated DEP. The fastest permeation was achieved by raising the temperature to $50{ }^{\circ} \mathrm{C}$ with PDMS membrane, reaching successfully total elimination of DEP in 5 days.

\section{References:}

[1] Gao, D.W. and Z.D. Wen, Phthalate esters in the environment: A critical review of their occurrence, biodegradation, and removal during wastewater treatment processes. Science of the Total Environment, 2016. 541: p. 986-1001.

[2] Dargnat, C., et al., Phthalate removal throughout wastewater treatment plant Case study of Marne Aval station (France). Science of the Total Environment, 2009. 407(4): p. 1235-1244.

[3] Starling, M.C.V.M., C.C. Amorim, and M.M.D. Leao, Occurrence, control and fate of contaminants of emerging concern in environmental compartments in Brazil. Journal of Hazardous Materials, 2019. 372: p. 17-36.

[4] Wilkinson, J., et al., Occurrence, fate and transformation of emerging contaminants in water: An overarching review of the field. Environmental Pollution, 2017. 231: p. 954970.

[5] Akhbarizadeh, R., et al., Worldwide bottled water occurrence of emerging contaminants: A review of the recent scientific literature. $J$ Hazard Mater, 2020. 392: p. 122271.

[6] He, M.J., et al., Phthalate esters in biota, air and water in an agricultural area of western China, with emphasis on bioaccumulation and human exposure. Science of the Total Environment, 2020. 698.

[7] Wittassek, M., et al., Assessing exposure to phthalates - The human biomonitoring approach. Molecular Nutrition \& Food Research, 2011. 55(1): p. 7-31.

[8] Dominguez-Morueco, N., S. Gonzalez-Alonso, and Y. Valcarcel, Phthalate occurrence in rivers and tap water from central Spain. Science of the Total Environment, 2014. 500: p. 139-146.

[9] Salazar-Beltrán, D., et al., Determination of phthalate acid esters plasticizers in polyethylene terephthalate bottles and its correlation with some physicochemical properties. Polymer Testing, 2018. 68: p. 87-94.

[10] Gao, D., et al., An overview of phthalate acid ester pollution in China over the last decade: Environmental occurrence and human exposure. Sci Total Environ, 2018. 645: p. 1400-1409.

[11] Luo, Q., et al., Migration and potential risk of trace phthalates in bottled water: A global situation. Water Research, 2018. 147: p. 362372.

[12] Luo, Q., et al., Migration and potential risk of trace phthalates in bottled water: A global situation. Water Res, 2018. 147: p. 362-372.

[13] Devier, M.H., et al., Ultra-trace analysis of hormones, pharmaceutical substances, alkylphenols and phthalates in two French natural mineral waters. Sci Total Environ, 2013. 443: p. 621-32.

[14] Jeddi, M.Z., et al., A margin of exposure approach to assessment of non-cancerous risk of diethyl phthalate based on human exposure from bottled water consumption. Environmental Science and Pollution Research, 2015. 22(24): p. 19518-19528.

[15] Akhbarizadeh, R., et al., Worldwide bottled water occurrence of emerging contaminants: A review of the recent scientific literature. Journal of Hazardous Materials, 2020. 392.

[16] Chen, X.P., et al., Toxicity and Estrogenic Endocrine Disrupting Activity of Phthalates and Their Mixtures. International Journal of Environmental Research and Public Health, 2014. 11(3): p. 3156-3168.

[17] Bertelsen, R.J., et al., Urinary Biomarkers for Phthalates Associated with Asthma in Norwegian Children. Environmental Health Perspectives, 2013. 121(2): p. 251-256.

[18] Hamid, N., et al., Prioritizing phthalate esters (PAEs) using experimental in vitro/vivo toxicity assays and computational in silico approaches. $J$ Hazard Mater, 2020. 398: p. 122851.

[19] Zhou, C., L. Gao, and J.A. Flaws, Prenatal exposure to an environmentally relevant phthalate mixture disrupts reproduction in F1 female mice. Toxicol Appl Pharmacol, 2017. 318: p. 49-57.

[20] Organization, W.H., Guidelines for drinkingwater quality: first addendum to the fourth edition. 2017.

[21] Kern, K., New Standards for the Chemical Quality of Water in Europe under the New Directive 2013/39/EU. Journal for European Environmental \& Planning Law, 2014. 11(1): p. 31.

[22] Sassi, H., et al., Wastewater treatment by catalytic wet air oxidation process over $\mathrm{Al}-\mathrm{Fe}$ pillared clays synthesized using microwave irradiation. Frontiers of Environmental Science \& Engineering, 2018. 12(1).

[23] El Assal, Z., et al., Catalytic abatement of dichloromethane over transition metal oxide catalysts: Thermodynamic modelling and 
experimental studies. Journal of Cleaner Production, 2019. 228: p. 814-823.

[24] da Silva, F.L., et al., Photocatalytic Degradation of Perfluorooctanoic Acid (PFOA) From Wastewaters by $\mathrm{TiO} 2$, In2O3 and $\mathrm{Ga} 2 \mathrm{O} 3$ Catalysts. Topics in Catalysis, 2017. 60(17-18): p. 1345-1358.

[25] Pesqueira, J.F.J.R., M.F.R. Pereira, and A.M.T. Silva, Environmental impact assessment of advanced urban wastewater treatment technologies for the removal of priority substances and contaminants of emerging concern: A review. Journal of Cleaner Production, 2020. 261.

[26] Rizzo, L., et al., Consolidated vs new advanced treatment methods for the removal of contaminants of emerging concern from urban wastewater. Sci Total Environ, 2019. 655: p. 986-1008.

[27] Eggen, R.I.L., et al., Reducing the Discharge of Micropollutants in the Aquatic Environment: The Benefits of Upgrading Wastewater Treatment Plants. Environmental Science \& Technology, 2014. 48(14): p. 7683-7689.

[28] Bourgin, M., et al., Evaluation of a full-scale wastewater treatment plant upgraded with ozonation and biological post-treatments: Abatement of micropollutants, formation of transformation products and oxidation. byproducts. Water Res, 2018. 129: p. 486-498.

[29] Kim, S., et al., Removal of contaminants of emerging concern by membranes in water and wastewater: A review. Chemical Engineering Journal, 2018. 335: p. 896-914.

[30] Haaz, E. and A.J. Toth, Methanol dehydration with pervaporation: Experiments and modelling. Separation and Purification Technology, 2018. 205: p. 121-129.

[31] Kanse, N.G., S.D. Dawande, and P.B. Dhanke, Effect of Feed Temperature and Solution Concentration on Pervaporation for separation of Azeotropic Mixtures. Materials Today: Proceedings, 2018. 5(2, Part 1): p. 3541-3550.

[32] Kanse, N.G. and S.D. Dawande, Separation of Ethanol/Water (Azeotropic mixture) by Pervaporation using PVA Membrane. Materials Today: Proceedings, 2017. 4(9): p. 1052010523.

[33] Dmitrenko, M.E., et al., Investigation of new modification strategies for PVA membranes to improve their dehydration properties by pervaporation. Applied Surface Science, 2018. 450: p. 527-537.

[34] Kaminski, W., J. Marszalek, and E. Tomczak, Water desalination by pervaporation -
Comparison of energy consumption. Desalination, 2018. 433: p. 89-93.

[35] Wang, Y., et al., Green recovery of hazardous acetonitrile from high-salt chemical wastewater by pervaporation. Journal of Cleaner Production, 2018. 197: p. 742-749.

[36] He, X., et al., Fabrication and characterization of micro-patterned PDMS composite membranes for enhanced ethanol recovery. Journal of Membrane Science, 2018. 563: p. 447-459.

[37] Žák, M., et al., Selective removal of butanol from aqueous solution by pervaporation with a PIM-1 membrane and membrane aging. Separation and Purification Technology, 2015. 151: p. 108-114.

[38] Šípek, M. and p. Česká membránová, Membránové dělení plynů a par. Vyd. 1. ed. 2014, Praha: Vysoká škola chemickotechnologická.

[39] Figoli, A., A. Cassano, and A. Basile, 10.3.3 Mixed-Matrix Membranes, in Membrane Technologies for Biorefining. Elsevier.

[40] Tsai, H.-A., et al., The preparation of polyelectrolyte/hydrolyzed polyacrylonitrile composite hollow fiber membrane for pervaporation. Journal of the Taiwan Institute of Chemical Engineers, 2018. 91: p. 623-633.

[41] Sorribas, S., et al., Pervaporation and membrane reactor performance of polyimide based mixed matrix membranes containing MOF HKUST-1. Chemical Engineering Science, 2015. 124: p. 37-44.

[42] Zhang, Y., et al., Pervaporation dehydration of acetic acid through hollow fiber supported DD3R zeolite membrane. Separation and Purification Technology, 2018. 204: p. 234-242.

[43] Moriyama, N., et al., Pervaporation dehydration of aqueous solutions of various types of molecules via organosilica membranes: Effect of membrane pore sizes and molecular sizes. Separation and Purification Technology, 2018. 207: p. 108-115.

[44] Ong, Y.K., et al., Recent membrane development for pervaporation processes. Progress in Polymer Science, 2016. 57: p. 1-31.

[45] Jankovsky, O., et al., Synthesis procedure and type of graphite oxide strongly influence resulting graphene properties. Applied Materials Today, 2016. 4: p. 45-53.

[46] Martin-Gil, V., et al., Study of different titanosilicate (TS-1 and ETS-10) as fillers for Mixed Matrix Membranes for $\mathrm{CO} 2 / \mathrm{CH} 4$ gas separation applications. Journal of Membrane Science, 2017. 523: p. 24-35. 
[47] Martin-Gil, V., et al., Effect of benzoic acid content on aging of 6FDA copolyimides based thin film composite (TFC) membranes in $\mathrm{CO} 2 / \mathrm{CH} 4$ environment. Separation and Purification Technology, 2019. 210: p. 616-626.

Contribution of individual authors to the creation of a scientific article (ghostwriting policy)

Flastimil Fíla and Jana Gaálová have cooperated on the conceptualization of the research. Mahdi Bourassi, Emma Humbert Martin and Mélanie Bourre have investigated the experiments. Mahdi Bourassi has wrote the original draft of publication. Jana Gaálová has reviewed and edited the publication. All authors have read and agreed to the published version of the manuscript.

\section{Sources of funding for research presented in a scientific article or scientific article itself}

This research was supported by the Czech Republic Foundation for grant No. 19-08153Y

\section{Creative Commons Attribution License 4.0 (Attribution 4.0 International, CC BY 4.0)}

This article is published under the terms of the Creative Commons Attribution License 4.0

https://creativecommons.org/licenses/by/4.0/deed.en_US 